\title{
REFLEXÕES SOBRE A PRÁTICA DE TUTORIA COM ESTUDANTES DE TERAPIA OCUPACIONAL
}

\author{
REFLECTIONS ON THE PRACTICE OF TUTORSHIP WITH OCCUPATIONAL THERAPY STUDENTS
}

\author{
Carla da Silva Santana 1 \\ Leonardo Martins Kebbe 2 \\ Marysia Mara R. P. de Carlo3 \\ Regina Y. Dakuzaku Carretta ${ }^{4}$ \\ Valéria Meirelles C. Elui ${ }^{5}$
}

Resumo Este artigo descreve experiência de tutoria desenvolvida no curso de graduação de Terapia Ocupacional na Faculdade de Medicina de Ribeirão Preto da Universidade de São Paulo (FMRP-USP), no âmbito dos modelos de práticas de tutoria desenvolvidas na formação em saúde, especificamente baseadas nas dimensões educativa e cuidativa. Trata-se de um estudo descritivo, no qual foi realizada pesquisa bibliográfica associada aos relatos dos docentes tutores. Os resultados mostram que a experiência de construção contínua de um curso superior universitário vai além do estabelecimento de estratégias de aquisição de saberes técnicos e que a formação deve estar voltada para o pleno exercício da interdisciplinaridade, necessária ao profissional da saúde de hoje, onde os lugares e valores entre os seus membros se traduzem num espaço dinâmico, em constante mudança. A experiência de tutoria permite o reconhecimento dos alunos e tutores como sujeitos ativos do processo formativo, que passa pela alteridade, pela legitimação da voz que é dada a cada uma das partes, pela percepção de que o conhecimento pode e deve ser construído numa relação mais horizontal entre seus atores.

Palavras-chave terapia ocupacional; tutoria; formação em saúde.
Abstract This article describes the guardianship experience developed in the undergraduate course of Occupational Therapy at the University of São Paulo's Ribeirão Preto School of Medicine (FMRP-USP), in the ambit of the guardianship practice models developed in health training based, specifically, on the educational and care dimensions. This is a descriptive study, in which a bibliographical survey was carried out in association to guardian reports. The results show that the experience of the ongoing construction of a course of study in higher education goes well beyond the definition of strategies for the acquisition of technical knowledge and that the training must be aimed at the full exercise of interdisciplinarity, which is necessary for the modern-day health professional, in which the places and values among its members translate into a dynamic, constantly mutant space. The guardianship experience allows for students and guardians to be acknowledged as subjects who are active in the training process, which goes through alterity, through the legitimation of the voice that is given to each one of the parts, through the perception of the fact that knowledge can and must be built in a more horizontal relationship among its players.

Keywords occupational therapy; guardianship; training in health. 


\section{Introdução}

O ensino no campo da saúde tem passado por importantes mudanças que advêm da necessidade, cada vez mais presente e urgente, de construir um processo de formação profissional pautada na ética e na perspectiva humanística, na reflexão crítica e construtiva sobre a relação entre professores e estudantes, assim como no reconhecimento do outro e de suas necessidades - seja este 'outro' um professor, aluno ou paciente, cliente ou usuário que recebe sua intervenção.

Como um caminho possível para a aproximação entre professores e alunos e para a realidade da vida universitária em sua multidimensionalidade, constitui-se a prática da tutoria. Essa estratégia vem ao encontro de uma ação mais humanizada no campo da educação em suas dimensões educativas e cuidativas, através do reconhecimento do aluno pela instituição como sujeito da prática e foco da ação educacional, dotado de valor como sujeito histórico.

O início da vivência universitária é marcado por uma série de mudanças, tanto na esfera privada quanto nas relações sociais. Estas têm coincidido com o ingresso na fase adulta, acompanhado da saída da casa dos pais, o estabelecimento de novos vínculos, a inserção em novos grupos, a organização dos estudos e das tarefas acadêmicas associada à recémconquistada liberdade e autonomia. Nesta fase de muitas dúvidas quanto ao curso da própria vida em transformação, a escolha e o investimento numa profissão podem ser assustadores e, muitas vezes, estão cercados de angústias e incertezas. Associa-se a isso o fato de que os métodos de ensino empregados continuam, em grande medida, a reproduzir as formas tradicionais de ensino em que o estudante é mero depositário de conhecimentos transmitidos pelos mestres.

Frente a essas mudanças de ordem pessoal e ao desafio inerente do ingresso na universidade, a prática de tutoria visa a criar um espaço de reflexão, individual e coletiva, sobre a experiência pessoal e acadêmica. Segundo Bellodi e Martins (2001), ao desenvolver um programa de tutoria, uma instituição permite mais oportunidades de identificar problemas de formação e possíveis encaminhamentos de soluções. Assim, espera-se que, com o compartilhar de experiências mediado por um ou dois tutores, os estudantes consigam aprender com as soluções aos problemas encontradas pelos outros integrantes do grupo e possam encontrar caminhos para responder a seus muitos dilemas e questionamentos. 


\section{Contextualizando o conceito de tutoria}

Tutoria é um termo polissêmico e tem sido definido em função dos contextos onde é utilizado. É possível encontrar um conjunto de características comuns nas diferentes concepções de tutoria universitária. De acordo com Carrasco Embuena e Lapeña Pérez (2005), estas podem ser sintetizadas da seguinte maneira: a) a tutoria é uma ação de orientação que visa a promover e facilitar o desenvolvimento integral dos estudantes, nas suas dimensões intelectual, afetiva, pessoal e social; b) é uma tarefa docente que personaliza a educação universitária mediante um acompanhamento individualizado, que facilita aos estudantes a construção e o amadurecimento dos seus conhecimentos e atitudes, ajudando-os no planejamento e no desenvolvimento do itinerário acadêmico; e c) é uma ação que permite a integração ativa e a preparação do estudante na instituição universitária, canalizando e dinamizando as suas relações com os diferentes serviços (administrativos, docentes, organizativos etc.).

Os programas de tutoria, o mentoring 6 e a tutoria curricular são algumas das formas encontradas em diversas instituições para dar resposta às necessidades de apoio e orientação aos alunos universitários. De acordo com Simão e Flores (2008), os programas de tutoria contribuem para a promoção de um sistema de formação integral dos estudantes e para o modelo educativo da instituição; para a concretização de um sistema de ensino mais flexível, em que o estudante gere com responsabilidade a construção de conhecimentos; e servem também para se compreender melhor as dificuldades acadêmicas dos estudantes e os modos de agir sobre elas num contexto de natureza não avaliativa. Baseados nos estudos de Mundina, Pombo e Ruiz (2007), Simão et al. (2008) sistematizaram (Quadro 1) alguns aspectos da tutoria:

Quadro 1

\begin{tabular}{ll}
\hline Alguns aspectos dos sistemas de tutoria \\
\hline Categoria & Indicadores \\
\hline Dimensões/modalidades & Administrativa, curricular, acadêmica, personalizada etc. \\
Objetivos & $\begin{array}{l}\text { Promover a aprendizagem de competências, consolidar } \\
\text { aprendizagens de disciplinas, promover e facilitar o } \\
\text { desenvolvimento integral dos estudantes, refletir sobre o } \\
\text { desenvolvimento acadêmico e pessoal do aluno etc. }\end{array}$ \\
Conteúdos & $\begin{array}{l}\text { Estratégias de aprendizagem, competências sociais, } \\
\text { competências comunicacionais etc. }\end{array}$ \\
Grupos-alvo & $\begin{array}{l}\text { Grupo curso, grupo ano escolar, grupo turma, aluno } \\
\text { individualmente considerado, aluno de educação à distância etc. }\end{array}$ \\
Tipos & Presencial, a distância, obrigatório, facultativo.
\end{tabular}


Continuação - Quadro 1

\begin{tabular}{ll}
\hline Alguns aspectos dos sistemas de tutoria \\
\hline Categoria & Indicadores \\
\hline Horários & $\begin{array}{l}\text { Dentro do horário escolar, não considerado dentro do horário } \\
\text { escolar etc. }\end{array}$ \\
Natureza & Encontros formais (aulas, reuniões), encontros informais etc. \\
Características & Turmas menores, número adicional de horas de tutoria etc. \\
Tutor & $\begin{array}{l}\text { Professor da unidade curricular, professor do curso, estudante do } \\
\text { último ano etc. }\end{array}$ \\
Avaliação & $\begin{array}{l}\text { Resultados positivos (maior proximidade professor-aluno, maior } \\
\text { facilidade de integração do aluno), constrangimentos (cansaço e } \\
\text { redução do rendimento por carga horária excessiva) etc. }\end{array}$
\end{tabular}

Fonte: Simão et al. (2008)

Nota: O quadro original foi modificado e adaptado ao idioma português utilizado no Brasil e suprimido exemplo específico da universidade portuguesa.

Baseado nas proposições de Geib et al. (2007), a tutoria pode estar fundamentada nas dimensões educativas e cuidativas, que nos remetem a um modelo de possibilidades para o futuro através de uma prática pedagógica orientada para o processo de humanização e de construção de soluções solidárias. Estas podem ser pensadas a partir das seguintes dimensões: educativa, que se caracteriza por oferecer ao aluno programas de suporte pedagógico e sua instrumentalização em técnicas e procedimentos para o desenvolvimento de habilidades para o estudo, a melhoria de seu desempenho acadêmico e a eficácia da aprendizagem. Procura também desenvolver no estudante a capacidade de comunicar-se de forma oral ou escrita e de participar dos movimentos sociais em nível estudantil, das associações profissionais e da comunidade em geral; e cuidativa, que procura cuidar do aluno, promovendo a ampliação de suas competências para viver, estudar e trabalhar de forma mais saudável (Geib et al., 2007).

\section{A experiência dos tutores}

A atuação do tutor na área de formação do profissional da saúde não costuma exigir curso ou treinamento psicológico especializado. Porém, espera-se que este apresente habilidades para a escuta e o compartilhamento de opiniões durante o exercício de suas funções (Bellodi e Martins, 2001). A expressão dessas habilidades nas ações da tutoria pode ser considerada como um processo de humanização do ensino, visto que 
(...) sendo o homem, provavelmente, o único ser vivente capaz de contar sua própria história pelo relato e leitura, o processo de humanizar baseia-se na atitude simples de se disponibilizar para ouvir e contar, trocar experiências e comparar seu processo histórico como outro. A identificação com esse outro, a reciprocidade de vidas e ações é que permite a identidade humana e o reconhecimento da possível imperfeição, mas também a ilimitada possibilidade do fazer de novo (Bellodi e Martins, 2001, p. 442).

O oferecimento da escuta e o desvelamento dos sujeitos narradores engendram uma relação interpessoal que passa pelo olhar daquele sujeito que se expressa e daquele que acolhe a experiência do outro. Bosi nos diz que

(...) esse novo olhar é o que, desde sempre exprime e reconhece forças e estados internos, tanto no próprio sujeito, que deste modo se revela, quanto no outro, com o qual o sujeito entretém uma relação compreensiva. A percepção do outro depende da leitura dos seus fenômenos expressivos dos quais o olhar é o mais prenhe de significações (Bosi, 1988, p. 77).

Olhar para o sujeito que se revela é também se deparar com os nossos próprios medos, experiências e vivências, como num espelho refletido, aprender nessa relação de coeducação. Nessa condição de aprendiz, através dos momentos de escuta e de convivência, na experiência do recontar e recordar, aprendemos a olhar além de nós mesmos e vamos produzindo conhecimento.

Alicerçados no pensamento de Bakhtin, citado por Geraldy (2003), entendemos que, ao estabelecer a prática da tutoria no âmbito acadêmico, estabelece-se uma relação dialógica baseada em dois pilares: a alteridade (pressupondo-se o 'outro' como existente e reconhecido pelo 'eu' como 'não-eu') e a dialogia (pela qual se qualifica a relação essencial entre o 'eu' e o 'outro'). Entretanto, assumir a relação dialógica como essencial na constituição dos seres humanos não significa imaginá-la sempre harmoniosa, consensual e desprovida de conflitos. Como também é reiterado pelo pensamento de Demo (2001), o diálogo é fala contrária entre atores que se encontram e se defrontam. Não se restringe à conversa; é, sobretudo, comunicação, com todos os seus riscos e desafios.

O encontro com o 'outro' que chega ao universo acadêmico abriga questões de alteridade, de diferenças, de diversidade. Com lugares de identidade e de alteridade, reconhece-se o estudante não apenas como um registro acadêmico, mas como membro de uma coletividade denominada 'universidade', como um sujeito histórico que habita nossos 'mundos-vidas'.

Porém, Deslandes e Assis (2002) consideram que, mesmo admitindo, como Dilthey, que o homem não é estranho ao outro homem - condição 
esta que nos habilita à interpretação -, não poderia ingenuamente crer que essa condição universal é suficiente. $O$ 'outro' é um território desconhecido, seja por possuir distintivos que socialmente nos separam, tais como status, classe, etnia, formação cultural e profissional e capital simbólico. Assim, a semelhança nos dá identidade como parte integrante do processo e, paradoxalmente, nos torna estrangeiros, posto estarmos em outra situação, no caso, nos lugares de tutores e de alunos com outra possibilidade de interlocução.

Além desses aspectos, um elo fundamental se impõe, autorizando esta 'fala-escuta' entre tutores e estudantes: o fato de lidarmos com o 'outro' que é sujeito de nossas intervenções clínicas. Semelhantes a nós mesmos na condição de humanidade que nos une, somos todos membros potenciais de uma relação terapêutica que se constrói permeada por aspectos étnicos, técnicos, de categoria, etários, culturais, religiosos, políticos...

\section{Contextualizando a prática da tutoria na Faculdade de Medicina de Ribeirão Preto}

A prática de tutoria foi adotada em 2006 no curso de graduação em terapia ocupacional da Faculdade de Medicina de Ribeirão Preto da Universidade de São Paulo (FMRP-USP). Este curso tem duração de cinco anos e é oferecido no período vespertino-noturno. No transcorrer da formação acadêmica, os docentes reconheceram a necessidade de ultrapassar uma relação meramente acadêmica e estabelecer estratégias de aproximação com os estudantes. Avaliamos que era preciso minimizar os muitos aspectos que distanciam todos os envolvidos e, para isso, optou-se por estabelecer uma relação tutor-aluno na perspectiva dialógica, entendendo-a como uma desafiadora tarefa para um curso de graduação que, até então, estava em implantação.

Espelhando-se no modelo já desenvolvido por outros cursos da Faculdade de Medicina, a graduação em terapia ocupacional desenvolveu uma tutoria ajustada à sua realidade e necessidade, ampliada para todos os anos e não apenas para o ano inicial, conforme já era desenvolvido no curso de medicina. Neste modelo, todas as turmas são acompanhadas pelos docentestutores (um ou dois tutores fixos durante todo o ano). Com as turmas do primeiro ano do curso, de acordo com o modelo institucional adotado, os encontros são quinzenais, deles participam dois docentes, um profissional integrante do Centro de Apoio Educacional e Psicológico da Faculdade de Medicina de Ribeirão Preto da Universidade de São Paulo (Caep) além de alunos dos anos anteriores. Os encontros duram cerca de uma hora, com periodicidade de um encontro mensal em horário comum a todos os alunos da turma. 
No que se refere à definição de qual docente será o tutor da turma, alguns aspectos importantes são considerados. O primeiro diz respeito à escolha de um professor que, preferencialmente, não tenha disciplinas com determinada turma naquele ano. Tal escolha pretende possibilitar que a própria prática docente possa ser questionada e discutida e preservar o distanciamento necessário que permita aos estudantes a liberdade de se expressarem sem prejuízo na relação aluno-professor. Tal organização é uma tarefa bastante paradoxal, pois ao mesmo tempo em que um professor mais distante permite o distanciamento necessário à escuta, isso também pode ser uma barreira à expressão dos alunos, relação esta que seria facilitada no caso de o docente estar em contato mais frequente com a turma, principalmente no caso dos graduandos de períodos iniciais do curso. O segundo aspecto se refere ao fato de que não há um tutor permanente, ou seja, o tutor muda anualmente. Embora esta mudança não se trate de uma condição inflexível, ela está atrelada à disponibilidade do docente, que, em geral, ministra um número menor de disciplinas com aquele mesmo grupo de alunos durante o ano. Também há ocorrência de um mesmo tutor permanecer na medida em que consegue estabelecer e fortalecer o vínculo com os alunos dos já tenha sido o tutor.

A aproximação entre tutores e estudantes muitas vezes acontece através da identificação: ambos fizeram a mesma escolha profissional, com questionamentos e dúvidas semelhantes quanto à opção feita; apresentaram conflitos relativos à passagem da adolescência à vida adulta, com todas as suas perspectivas sedutoras e ameaçadoras; e sentiram as mesmas angústias em relação à tarefa de explicar e definir a terapia ocupacional, em suas características profissionais, sua identidade, dentre outros aspectos. Porém, nem sempre essa identificação é suficiente para estabelecer um diálogo franco e aberto quando os temas são muito conflituosos. De qualquer forma, sejam quais forem os assuntos abordados, os tutores têm o compromisso de encaminhar os apontamentos trazidos pelos alunos à coordenação e ao colegiado docente do curso.

As atividades desenvolvidas como estratégias facilitadoras da discussão geral são de responsabilidade dos tutores, que lançam mão de várias técnicas de mobilização grupal. Ocorrem dinâmicas de grupo, atividades de dramatização, tais como o role playing, ${ }^{7}$ atividades de recorte e colagem, entre outras. Os assuntos emergem dos apontamentos dos membros do grupo e são discutidos no âmbito do coletivo. Em geral, há uma síntese dos assuntos ao final da reunião e a tarefa de retomar, no encontro seguinte, os desdobramentos dos temas trazidos a partir dos encaminhamentos feitos.

Alguns apontamentos dos graduandos podem ser resolvidos na própria tutoria, que acolhe tais demandas, no caso de situações de necessidade de orientação, de informação para tomada de decisão, reflexões e mesmo 
expressão de desejos, angústias e necessidades. Algumas demandas referem-se a questões vinculadas às disciplinas ou relações discente-docente específicas, situação em que se estimula o desenvolvimento de diálogo entre as partes, na busca de solução para a melhoria da comunicação no processo ensino-aprendizagem. Em outras situações, as demandas precisam ser discutidas de forma mais ampla, como nos fóruns descritos a seguir.

\section{‘Fórum': local de encaminhamentos e devolutivas}

O 'fórum' é um espaço ampliado para discussões, para onde as questões mais relevantes são levadas pelos representantes discentes de cada turma, juntamente com os docentes tutores. Nesta reunião, ocorre uma devolutiva dos encaminhamentos já realizados e a discussão dos assuntos mais recentes.

O fórum de discussão ocorre de duas a três vezes por semestre e tem duração de cerca de noventa minutos. Durante a discussão, há uma inversão de papéis adotados nas reuniões de tutoria, quando os temas são trazidos pelos alunos e a discussão é mediada pelo tutor. No fórum, quem narra a discussão são os tutores e, muitas vezes, o papel do aluno é complementar a fala do tutor, exemplificar em caso de dúvida, acompanhar se as discussões trazidas de fato traduzem o acontecido e participar das discussões.

Este encontro apresenta estratégias específicas de discussão. A primeira etapa refere-se à socialização dos problemas, quando todo o grupo toma ciência das questões vividas pelos alunos de diferentes turmas. Ocorre, então, a mobilização, tanto dos alunos de outras turmas como também do tutor, que manifesta se fez algum encaminhamento para resolução de determinadas situações. Nesta experiência de compartilhamento, as questões podem ser mais facilmente compreendidas e resolvidas.

Neste processo, pode ocorrer a identificação de dificuldades cíclicas, ou até mesmo crônicas, que se repetem. O grupo pode identificar que viveu anteriormente este mesmo processo colocado em discussão e reconhecer que os encaminhamentos feitos em outro momento não foram efetivos para solucionar a situação. Por exemplo, um tema recorrente é o da necessidade de discussão, com os responsáveis por determinadas disciplinas básicas ou clínicas (os quais, geralmente, têm formação médica), acerca da necessidade de adequação do conteúdo desenvolvido à formação aos profissionais nãomédicos da área da saúde. Tal processo é bastante desgastante para os tutores e alunos. Em geral, orienta-se que os alunos procurem discutir as dificuldades diretamente com os docentes das disciplinas. Caso não haja solução, o tutor e o coordenador do curso tentam a intermediação com o docente na busca da resolução para o problema específico. 
A tarefa de buscar soluções está muito longe de ser fácil, principalmente porque implica muitas vezes no confronto com a tradição médica e seu modus operandi, com as arrogâncias pessoais e com a necessidade de exercício do poder. As soluções precisam estar pautadas no reconhecimento da legitimidade do outro, da complexidade do humano a quem se destinam as ações educativas, sociais e de saúde, e estas requerem uma abordagem em saúde e educação mais integradora. De acordo com Saupe et al. (2005), na perspectiva contemporânea, a interdisciplinaridade contempla: o reconhecimento da complexidade crescente do objeto das ciências da saúde e a consequente exigência interna de um olhar plural; a possibilidade de trabalho conjunto, que respeita as bases disciplinares específicas, mas busca soluções compartilhadas para os problemas das pessoas e das instituições; e o investimento como estratégia para a concretização da integralidade das ações de saúde. No entanto, o trabalho de mediação precisa estar além da escuta e do encaminhamento dos questionamentos às pessoas de destino. A tutoria busca ser um facilitador na construção das soluções, e estas transcendem este espaço devendo alcançar todos os envolvidos na formação.

A prática de refletir e diagnosticar os problemas enfrentados no curso de terapia ocupacional busca concretizar uma formação mais integral, desenvolvendo as competências necessárias a um profissional da saúde que vão além do saber técnico. Assim, a tutoria traduz-se num espaço fecundo para o desenvolvimento destas competências. Como refere Amâncio Filho (2004), é preciso reconhecer a necessidade de uma formação profissional orientada para o trabalho - entendido como processo de humanização do homem -, que objetive integrar conhecimentos gerais e específicos, habilidades teóricas e práticas, hábitos, atitudes e valores éticos. Assim, é necessário

desenvolver as habilidades comunicativas (capacidade de expressão e de comunicação com seu grupo, superiores hierárquicos ou subordinados, cooperação, trabalho em equipe, diálogo, exercício da negociação), as capacidades sociais (capacidade de transferir conhecimentos da vida cotidiana para o ambiente de trabalho e vice-versa) e as habilidades comportamentais, como iniciativa, criatividade, vontade de aprender, abertura às mudanças e consciência da qualidade e das implicações éticas do seu trabalho (Deluiz, 1998, apud Amâncio Filho, 2004, p. 378).

\section{Os diferentes questionamentos trazidos pelos estudantes ao longo dos anos}

Os questionamentos se diferenciam segundo o ano do curso de graduação e os desafios que se impõem conferem características especiais e identidade 
para cada turma. O primeiro ano do curso é marcado por mudanças relativas ao ingresso na universidade e o estabelecimento de novas relações - com os familiares, com os amigos antigos e os novos, com os professores e com a própria universidade, com sua nova dinâmica de ensino bastante diferenciada daquela vivida durante o Ensino Médio. Como a maior parte dos alunos do curso de terapia ocupacional da FMRP-USP não é originária do município de Ribeirão Preto, a saída da casa dos pais costuma marcar também a difícil tarefa de lidar com o livre-arbítrio e com as consequências das escolhas realizadas. Este tema emerge quer estejamos falando da escolha da profissão e o que isto significa no momento presente e no futuro, quer seja sobre a contraposição entre as demandas de estudo e as muitas opções de lazer características da vida acadêmica. Assim, os questionamentos que estes estudantes levantam vão desde dificuldades de instalação na cidade, relativos à moradia, até informações sobre o funcionamento da universidade. Eles também trazem os problemas relativos à angústia de separação dos familiares a cada retorno nos feriados e finais de semana.

Outra questão relevante para os estudantes da etapa inicial da formação superior em terapia ocupacional é a dificuldade de se relacionar com um grande número de disciplinas básicas biológicas, como Anatomia e Fisiologia, dentre outras. A grande concentração de disciplinas básicas nos anos iniciais, aliada à alta exigência acadêmica advinda de certo tipo de conhecimento (fundamentalmente biomédico), dificulta uma maior aproximação e vivência em relação às disciplinas de formação específica do curso e compromete a percepção dos estudantes acerca da terapia ocupacional. Os estudantes demonstram dificuldades de compreender a necessidade desses conhecimentos básicos ministrados (que costumam ser apresentados de forma muito fragmentada) para a sua formação profissional. Acresce-se a isso o fato de que os professores das áreas básicas, com diferentes formações, não conseguem relacionar seus conhecimentos específicos com a aplicação prática nas áreas profissionais da terapia ocupacional. É frequente a impressão de que estão falando para futuros médicos e que não sabem que estão lidando com estudantes de diferentes profissões da área da saúde. Estas questões podem ser traduzidas pela falta de exemplos baseados na prática específica da área de formação e de conhecimento acerca da importância de como determinado conteúdo se insere na formação daquele profissional, quando não ocorre de o professor desconhecer aspectos cruciais, tais como o objeto de conhecimento do terapeuta ocupacional e para quem as suas ações se destinam. Contudo, estas questões revelam a falta de articulação entre os atores envolvidos na formação e a fragmentação do conhecimento. De acordo com Mangia (1999), o fato de os terapeutas ocupacionais articularem seus estudos com outras disciplinas, tais como Sociologia, Psicologia, Antropologia, Artes e Educação, estabelece um fecundo campo de recortes positivos na 
constituição da multiplicidade de discursos da terapia ocupacional. No entanto, não podemos esquecer que a terapia ocupacional nasce de um campo de práticas e posteriormente vai construindo um campo de conhecimento, os quais são diversos e heterogêneos em suas ações e em seu sistema de valores e de crenças. A terapia ocupacional ganha um redimensionamento importante no berço da interdisciplinaridade. Assim, está posto o grande desafio que é o diálogo entre as partes, atores da formação e consequentemente das diferentes disciplinas. Tal ação implica na abertura ao novo, ao outro e a sua legitimidade.

No segundo ano do curso, os estudantes parecem mais bem adaptados à vida universitária, existindo, inclusive, a incumbência de que recepcionem os 'calouros' no momento de matrícula. Para isso, desenvolveram a prática de 'apadrinhamento', sendo cada um responsável (como 'madrinhas' e 'padrinhos-tutores') por acompanhar os calouros em seu primeiro ano e ajudá-los a resolver suas dificuldades. Porém, esta passagem da condição de calouros para veteranos, em apenas um ano, também costuma ser conflituosa, uma vez que estão há pouco tempo na universidade e ainda vislumbram de forma precária sua formação profissional.

Os questionamentos e as dúvidas sobre as disciplinas básicas e clínicas continuam e fazem crescer as expectativas e os desejos sobre a maior aproximação das práticas em terapia ocupacional, para melhorar a percepção do estudante sobre sua carreira. Isso exige dos docentes o planejamento de disciplinas específicas com maior articulação em questões da prática profissional ainda não vivenciada pelos estudantes. Porém, este segundo ano costuma ser bastante crítico no que se refere à opção pela continuidade ou interrupção da formação. Embora este tema não seja muito explicitado publicamente, as dúvidas e indecisões individuais sobre se certos estudantes continuarão ou não na carreira trazem uma tonalidade angustiante para as reuniões grupais.

O terceiro ano é marcado pelo incremento da formação específica do curso, com o início das disciplinas aplicadas de conhecimentos específicos. Muitos estudantes, neste período, preocupam-se com sua formação complementar, buscando atividades extracurriculares optativas e de iniciação científica. Apesar de continuarem os questionamentos sobre as disciplinas de formação não-específicas (disciplinas clínicas), eles costumam lidar com esses docentes de forma mais afirmativa, com maior necessidade de se sentirem reconhecidos como terapeutas ocupacionais.

No quarto ano, além do incremento das disciplinas teórico-práticas de formação específica, nova demanda se impõe, geralmente acompanhada de grande angústia. Há, ainda, a necessidade de realização dos trabalhos de conclusão de curso, que são desenvolvidos ao longo de quatro disciplinas diferentes denominadas Pesquisa em Terapia Ocupacional I, II, III e IV. 
Há que se esclarecer que a Pesquisa IV, implantada oficialmente em 2007, volta-se à necessidade de transformar os trabalhos desenvolvidos em artigos a serem publicados em periódicos científicos, respondendo à forte demanda institucional de ampliação das publicações conjuntas.

O quinto ano é marcado pelos desafios das práticas profissionalizantes, através da realização de estágios em três áreas distintas (duas obrigatórias e uma eletiva), mas é um ano também repleto de expectativa quanto à saída da universidade (formatura) e concretização de seus planos para a vida profissional. Aparecem conflitos relacionados tanto às dificuldades inerentes aos estágios e às monografias quanto à sensação de não estarem formados e prontos para o mercado de trabalho.

\section{Discussão}

O relato da experiência de tutoria nos permitiu olhar para a nossa prática como tutores e docentes e extrair desta vivência algumas reflexões. Uma delas se refere ao fato de que, embora os professores deste curso de terapia ocupacional tenham de seis a 18 anos de experiência docente, defrontam-se constantemente com questões pedagógicas relativas à formação em saúde que vão muito além do ensino de competências técnicas para o exercício profissional do terapeuta ocupacional.

O reconhecimento dos estudantes e tutores como sujeitos ativos do processo formativo passa pela alteridade, pela legitimação da voz que é dada a cada uma das partes, pela percepção de que o conhecimento pode e deve ser construído numa relação mais horizontal entre seus atores. E esta relação de horizontalidade não deve estar resumida na relação tutor-estudante, mas ampliar-se em direção à instituição formadora com todos os seus atores envolvidos: docentes das demais disciplinas e administradores, caso contrário a prática de tutoria correrá o risco de ter o seu papel pedagógico comprometido. Conforme refere Saupe et al. (2005), docentes e profissionais dos serviços necessitam construir e ressignificar suas próprias capacidades tanto na área educacional como na de cuidado à saúde de pacientes e comunidades. A relação educacional, como constrói e ressignifica saberes, requer maior horizontalização, ação cooperativa, solidária e ética, postura ativa, crítica e reflexiva, desenvolvimento da capacidade de aprender a aprender, identificação dos próprios valores e abertura para a superação de limites e construções.

Como refere Costa Neto,

é urgente que se estabeleça uma nova relação entre os profissionais de saúde (...) diferentemente do modelo biomédico tradicional, permitindo maior diversidade 
das ações e busca permanente do consenso. Tal relação, baseada na interdisciplinaridade e não mais na multidisciplinaridade (...) requer uma abordagem que questione as certezas profissionais e estimule a permanente comunicação horizontal entre os componentes de uma equipe (Costa Neto, 2000, p. 9).

De acordo com Amâncio Filho (2004), nesse percurso de formação profissional, é necessário aprofundar a reflexão sobre os meios e os modos como a formação vem ocorrendo, isto é, questionar se os conteúdos curriculares e as metodologias de ensino utilizadas permitem ao aluno apreender tanto os procedimentos técnicos indispensáveis ao exercício profissional como, também, desenvolver visão crítica em relação ao processo de trabalho e ao mundo que o circunda. Nesta perspectiva, a figura do professor inquestionável em seu conhecimento e do aluno como um receptáculo passivo já não são mais admitidos, pois o conhecimento é gestado e cuidado por todos.

A tutoria aparece como uma possibilidade de cuidado entre os atores nas mais variadas vivências, tanto acadêmicas como pessoais. É preciso instituir estratégias que escapem a padrões convencionais de educação, como a implantação e o desenvolvimento, na esfera da educação profissional, de projetos dinamizadores do uso de novas tecnologias, promovendo e articulando o conhecimento produzido com as necessidades que (re)configuram a sociedade atual.

Nesta perspectiva, a vivência da tutoria traz aos alunos, aos tutores e à instituição a perspectiva de construção de uma prática de formação num mundo cambiante. Envolve a discussão sobre temáticas diversas, desde a relação entre professores e alunos, a pertinência de determinadas práticas institucionais e conteúdos dos componentes curriculares e o contexto de atuação profissional, até as características pessoais do profissional que se forma conhecendo gradativamente a realidade do contexto da saúde onde exercerá sua prática.

Portanto, traz a necessidade de pensar a inserção e os modos de participação na realidade que vem sendo moldada, construindo o futuro a partir da assimilação, da reflexão, do questionamento e da formulação de propostas calcadas na realidade objetiva em que cada um se insere. A partir daí poderão ser elaboradas e implementadas estratégias políticas visando a transformar essa mesma realidade.

Apoiado nas considerações de Deluiz (1997), sobre os requerimentos da dinâmica profissional, o trabalhador deve possuir capacidade de diagnóstico, de solucionar problemas, de tomar decisões, de intervir no processo de trabalho, de atuar em equipe, de auto-organizar-se. Como mencionado, é preciso pensar uma formação profissional orientada para o trabalho - entendido como processo de humanização do homem -, que objetive integrar conhecimentos gerais e específicos, habilidades teóricas e práticas, hábitos, 
atitudes e valores éticos. A educação torna-se fundamental, portanto, para que os indivíduos dominem as ciências (físicas, químicas e biológicas), as linguagens (a matemática, as línguas, a informática, as artes e a expressão corporal) e os estudos do homem (a história, a geografia, a sociologia, a economia e a filosofia) para que possam compreender e atuar no mundo social e cultural no qual estão inseridos (Deluiz, 1997, p. 17).

Finalizando, a experiência de construção contínua de um curso superior universitário vai muito além do estabelecimento de estratégias de aquisição de saberes técnicos. Deve ser um processo através do qual o saber vai perpassando as relações, as dificuldades do dia-a-dia e os encantos e desafios que esta experiência propicia. A tutoria aparece como possibilidade concreta de compartilhar esta experiência pautada numa nova perspectiva de formação em saúde.

\section{Notas}

1 Professora do Departamento de Neurociências e Ciências do Comportamento da Faculdade de Medicina de Ribeirão Preto da Universidade de São Paulo (FMRP-USP), Ribeirão Preto, São Paulo, Brasil. Doutora em Psicologia Escolar e do Desenvolvimento Humano pela Universidade de São Paulo (USP). <carla.santana@fmrp.usp.br> Correspondência: Rua Maestro Joaquim Thomé Leite, 684, Jardim Castelo Branco, Ribeirão Preto, São Paulo, Brasil, CEP 14090-610.

2 Professor do Departamento de Neurociências e Ciências do Comportamento da Faculdade de Medicina de Ribeirão Preto da Universidade de São Paulo (FMRP-USP), Ribeirão Preto, São Paulo, Brasil. Doutor em Enfermagem em Saúde Pública pela Universidade de São Paulo (USP). <kebbe@fmrp.usp.br>

3 Professora do Departamento de Neurociências e Ciências do Comportamento da Faculdade de Medicina de Ribeirão Preto da Universidade de São Paulo (FMRP-USP), Ribeirão Preto, São Paulo, Brasil. Doutora em Educação pela Universidade Estadual de Campinas (Unicamp). <marysia@fmrp.usp.br>

4 Professora do Departamento de Neurociências e Ciências do Comportamento da Faculdade de Medicina de Ribeirão Preto da Universidade de São Paulo (FMRP-USP), Ribeirão Preto, São Paulo, Brasil. Doutora em Engenharia de Produção pela Universidade Federal de São Carlos (UFSCar). <reginadc@fmrp.usp.br>

5 Professora do Departamento de Neurociências e Ciências do Comportamento da Faculdade de Medicina de Ribeirão Preto da Universidade de São Paulo (FMRP-USP), Ribeirão Preto, São Paulo, Brasil. Doutora em Engenharia de Produção pela Universidade Federal de São Carlos (UFSCar).<reginadc@fmrp.usp.br> 
6 De acordo com Simão e Flores (2008), a definição do termo mentoring constitui um dos desafios que se colocam aos estudos nesta área, dado que o termo pode ser próximo e, por vezes, confundido com outros, tais como tutoria e aconselhamento ou até orientação ou supervisão (Pereira, 2005; Denisson, 2000; Barnett, 2008; Rose e Rukstalis, 2008; Colvin, 2007), coaching e ensino (Healy, 1997). O que distingue o mentoring de outros tipos de relações de ajuda ou de ensino é o seu propósito de atuar num processo de transição ajudar alguém a passar de um estado para outro (Wallace e Gravells, 2005).

7 O termo role playing foi introduzido por Moreno (1974) e traduz-se pela 'interpretação de papéis'. "O jogo ou treinamento de papéis permite explorar as possibilidades de um indivíduo de representar os papéis determinados..." (Moreno, 1974, p. 122). Na metodologia psicodramática terapêutica, recursos como o sociodrama, o role playing, as modalidades educativas do teatro espontâneo e do jornal vivo e os jogos dramáticos são atividades que podem ser usadas em situações de aprendizagem como recursos facilitadores da compreensão de fenômenos que envolvem inter-relações pessoais (Romaña, 1996).

\section{Referências}

AMÂNCIO FILHO, Antenor. Dilemas e desafios da formação profissional em saúde. Interface: Comunicação, Saúde, Educação, v. 8 , n. 15, p. 375-380, mar.-ago. 2004.

BARNETT, Jeffrey E. Mentoring, boundaries, and multiple relationships: opportunities and challenges. Mentoring \& Tutoring: Partnership in Learning, v. 16, n.1, p. 3-16, 2008.

BELLODI, Patrícia Lacerda; MARTINS, Milton de Arruda. Projeto tutores: da proposta à implantação na graduação da Faculdade de Medicina da Universidade de São Paulo (FMUSP). Hospital Universitário, v. 11, n. 1-2, p. 52-58, 2001.

BOSI, Alfredo. Fenomenologia do olhar. In: NOVAES, Adauto et al. O olhar. São Paulo: Companhia da Letras, 1988. p. 65-87.

COLVIN, J. W. Peer tutoring and social dynamics in higher education. Mentoring \& Tutoring: Partnership in Learning, v. 15, n. 2, p. 165-181, 2007.

CARRASCO EMBUENA, Vicente; LAPEÑA PÉREZ, Cristina. La Acción Tutorial en la
Universidad de Alicante. Investigar el diseño curricular: redes de docencia en el Espacio Europeo de Educación Superior. v. 2. Alicante: Universidade de Alicante, 2005.

COSTA NETO, Milton Menezes da (Org.). A implantação da Unidade de Saúde da Família. Brasília: Ministério da Saúde, Secretaria de Políticas da Saúde, Departamento de Atenção Básica, 2000.

DELUIZ, Neise. Neoliberalismo e educação: é possível uma educação que atenda os interesses dos trabalhadores? Tempo e Presença, n. 293, p. 14-16, mai./jun. 1997.

DEMO, Pedro. Pesquisa: princípio científico e educativo. 8. ed. São Paulo: Cortez, 2001.

DENNISON, Susan. A win-win peer mentoring and tutoring program: a collaborative model. The Journal of Primary Prevention, v. 20, n. 3, p. 161-174, 2000.

DESLANDES, Suely Ferreira; ASSIS, Simone Gonçalves. Abordagens quantitativa e qualitativa em saúde: o diálogo das diferenças. In: MINAYO, Maria Cecília de Souza. (Org.) Caminhos do pensamento: epistemologia e 
método. Rio de Janeiro: Fiocruz, 2002. p. 195-226.

DILTHEY, Wilhelm. Introducción a las ciencias del espiritu. Alianza Editorial, Madri, 1986.

GEIB, Lorena Teresinha Consalter et al. A tutoria acadêmica no contexto histórico da educação. Revista Brasileira de Enfermagem, v. 60, n. 2, p. 217-220, 2007.

GERALDY, João Wanderley. A diferença identifica. A desigualdade deforma. Percursos bakhtinianos de construção ética e estética. In: FREITAS, Maria Teresa; JOBIM, Solange; KRAMER, Sônia (Orgs.) Ciências Humanas e Pesquisa: leituras de Mikhail Bakhtin. São Paulo: Cortez, 2003. p. 39-56.

HEALY, C. C. An Operational Definition of Mentoring. In: FRIERSON JR., H.T. Diversity in Higher Education. Londres: Jai Press Inc, p. 9-22, 1997.

MANGIA, Elisabete Ferreira. Terapia Ocupacional: práticas, discursos e a questão da legitimidade científica. Revista de Terapia Ocupacional, v. 10, n. 2/3, p. 55-59, mai./dez. 1999.

MORENO, Jacob Levy. Psicoterapia de Grupo e Psicodrama. São Paulo: Mestre Jou, 1974.

MUNDINA, Julia Boronat; POMBO, Nieves Castaño; RUIZ, Elena Ruiz. Dimensión convergente de la tutoría en la universidad: tutoría entre iguales. In: JORNADAS DE REDES DE INVESTIGACIÓN EN DOCENCIA UNIVERSITÁRIA, 5, 2007, Alicante. Alicante: Universidad de Alicante, 2007. Disponível em: <www.eduonline.ua.es/ jornadas2007/comunicaciones/2G3.pdf $>$. Acesso em: jan. 2008.
PEREIRA, Anabela M. S. Para obter sucesso na vida académica: apoio dos estudantes pares. Aveiro: Universidade de Aveiro, theoria poiesis praxi, 2005.

ROMAÑA, Maria Alícia. Do psicodrama pedagógico à pedagogia do drama. Campinas: Papirus, 1996.

ROSE, G. L. \& RUKSTALIS, Margaret R. Imparting medical ethics: the role of mentorship in clinical training. Mentoring \& Tutoring: Partnership in Learning, v. 16, n.1, p. 77-89, 2008.

SAUPE, Rosita et al. Competência dos profissionais da saúde para o trabalho interdisciplinar. Interface: Comunicação, Saúde, Educação, v. 9, n. 18, p. 521-536, set./dez. 2005.

SIMÃO, Ana Maria Veiga et al. Tutoria no ensino superior: concepções e práticas. Sísifo: Revista de Ciências da Educação, n. 7, p. 75-88, set/dez 2008.]

SIMÃO, Ana M. V.; FLORES, Maria A. Experiências de tutoria: problemas e desafios. Disponível em: <www.eduonline.ua.es/ jornadas2008/comunicaciones/2D2.pdf?PH PSESSID $=$ ef2 $4605509051626325 \mathrm{cff} 2 \mathrm{af} 4 \mathrm{bfd}$ 7bf>. Acesso em: 7 mar. 2009.

WALLACE, S.; GRAVELLS, J. Professional Development. Lifelong Learning Sector: Mentoring. Learning Matters, 2005.

Recebido em 04/11/2008

Aprovado em 03/03/2009 